\title{
"A MULHER DE PRETO": REFERÊNCIAS À MODA COMO ESTRATÉGIA PARA A PROBLEMATIZAÇÃO DO PROJETO EDITORIAL DO JORNAL DAS FAMÍLIAS
}

\section{JOSILENE LUCAS DA SILVA}

Universidade de São Paulo

São Paulo, São Paulo, Brasil

Resumo: Os contos iniciais de Machado de Assis foram publicados no Jornal das Famílias (1863-1878) em meio a receitas culinárias, dicas de maquiagem e moda. Esses escritos parecem alinhados ao projeto editorial desse periódico porque também exploram temas considerados amenos. No entanto, se na aparência esses escritos seguiam imposições editoriais, um outro olhar sobre eles revela que o autor tentou problematizar alguns desses temas. Acreditamos que para isso se valeu das referências à moda. Para demonstrar essa hipótese será apresentado um estudo do projeto editorial do referido periódico e com base nele será feita uma análise das menções à moda no conto "A mulher de preto" publicado nessa revista entre abril e maio de 1868.

Palavras-chave: Machado de Assis; conto; moda; Jornal das Famílias

\section{"WOMAN IN BLACK": REFERENCES TO FASHION AS A STRATEGY FOR QUESTIONING THE EDITORIAL AGENDA OF THE JORNAL DAS FAMÍLIAS}

Abstract: Machado de Assis's first short stories were published in the Jornal das Famílias (1863-1878) amid recipes and fashion and makeup tips. These writings seem to be aligned to the magazine's editorial agenda, because they deal with issues considered to be soft. However, whereas these writings appear to have followed editorial constraints, another perspective reveals that the author attempted to question some of these topics. We believe that this is the reason he made references to fashion in these short stories. A study of the editorial design of this journal will be presented to demonstrate this hypothesis and will underpin an analysis of the short story "The Woman in Black" - published in that magazine between April and May, 1868.

Keywords: Machado de Assis; short story; fashion; Jornal das Famílias 


\section{Considerações iniciais}

$\mathrm{M}$ achado de Assis iniciou sua carreira escrevendo em jornais e revistas brasileiros do século XIX. Grande parte de seus escritos, antes de ser lançada em volumes, foi publicada nesses periódicos. É o caso das duas primeiras coletâneas de contos do autor, Contos fluminenses (1870) e Histórias da meia-noite (1873), que abrangem seus escritos iniciais que, com exceção de "Miss Dollar", apareceram antes no Jornal das Famílias, entre 1864 e 1873.

Este artigo pretende discutir a relação entre o conteúdo do Jornal das Famílias e as referências a elementos da moda no conto "A mulher de preto"1 publicado nesse periódico entre abril e maio de 1868 -, a fim de mostrar como essas menções contribuem para aprofundar as discussões de questões como a educação das mulheres. Essa narrativa, mesmo inserida numa publicação conservadora, que exigia literatura amena de seus colaboradores, parece questionar, por meio de alusões à moda, assuntos considerados frívolos, mas que eram priorizados pela revista.

Cabe esclarecer que o termo "moda" será usado no seu sentido mais restrito, relacionado às mudanças periódicas nos estilos de vestimenta e nos demais detalhes de ornamentação pessoal. ${ }^{2}$ Além disso, mais do que falar sobre as roupas das personagens e seu enquadramento nas modas vigentes, serão consideradas também as opiniões delas e do narrador sobre o tema.

\section{O perfil conservador do Jornal das Famílias (1863-1878) e o aparente alinhamento dos contos iniciais de Machado de Assis}

O Jornal das Famílias, ${ }^{3}$ criado por Baptiste Louis Garnier, circulou por dezesseis anos, entre 1863 e 1878, com colaboração assídua de Machado de Assis. Foi uma continuação da Revista Popular - periódico também dirigido por Garnier e que circulou entre 1859 e 1862. Esta publicação era quinzenal, dedicada às letras, às ciências e às artes, e direcionada a um público erudito; ${ }^{4}$ aquela era mensal e

\footnotetext{
${ }^{1}$ Jornal das Famílias, abr.-maio de 1868. ASSIS, Obra completa em quatro volumes, v. 2, p. 43-63.

2 Ver mais em: SOUZA, O espírito das roupas: a moda no século XIX.

3 Todas as citações retiradas do Jornal das Famílias têm como referência a coleção disponível no site da Hemeroteca Digital Brasileira da Biblioteca Nacional e serão identificadas pelo nome da revista, mês, ano de publicação e número da página. Além disso, nas citações diretas será respeitada a grafia original.

${ }^{4}$ Ver mais sobre a Revista Popular em: PINHEIRO, Revista Popular (1859-1862) e Jornal das Famílias (18631878): dois empreendimentos de Garnier, 2002.
} 
"exclusivamente dedicada aos interesses domésticos das famílias brasileiras" como revela o editorial da primeira edição. ${ }^{5}$

Estudar as páginas dessa revista nos ajuda a entender o que era considerado interesse doméstico: receitas culinárias, dicas para eliminar lagartas ou para aliviar queimaduras, poesias de cunho sentimental, além de ensinamentos religiosos. Havia também uma seção literária intitulada "Romances e Novelas", na qual foram publicados os primeiros contos de Machado. O Jornal das Famílias apresentava também um suplemento com figurinos que seguiam as últimas tendências da moda em Paris. Modelos franceses de trajes e combinações para diferentes ocasiões (passeios e festas) representavam o ideal de elegância que se buscava no Brasil naquele período. Além disso, publicavam-se desenhos de bordados, pontos de crochê e de renda.

Esse suplemento de moda atraía o público feminino. Considerando os demais temas abordados, relacionados sempre à esfera doméstica, é possível dizer que esse era o público pretendido pelo periódico, já que as tarefas da casa - ou a orientação dos criados para realizá-las -, incluindo-se os cuidados com o marido e com os filhos, eram reservadas às mulheres. ${ }^{6}$ Assuntos como política e ciência não eram considerados parte do universo feminino. ${ }^{7}$

A revista ainda prometia zelo na escolha dos seus artigos, priorizando aqueles que "mais importassem ao país, à economia doméstica, à instrução moral e recreativa, e à higiene". ${ }^{8}$ Em outras palavras, a publicação pretendia ser útil na vida das famílias com a difusão de valores socialmente aceitos e o entretenimento das mulheres.

Considerando que a maior parte das famílias brasileiras naquele momento era composta por analfabetos ${ }^{9}$ e que poucos tinham condições financeiras para adquirir o periódico, é possível dizer que a revista era direcionada à família burguesa que mantinha esse tipo de publicação pagando pelas assinaturas. Para garantir a venda dos exemplares preenchiam-se as páginas com assuntos dos quais as mulheres podiam se ocupar. Além disso, ao esclarecer no editorial da primeira edição que publicariam artigos que visassem à instrução moral de seus leitores, revela-se que a missão da revista também era preservar e difundir os valores morais da burguesia brasileira.

Para divulgar os valores socialmente aceitos pela burguesia - como o recato das moças antes do casamento e, posteriormente, a sujeição aos maridos -, a

\footnotetext{
${ }^{5}$ Jornal das Famílias, jan. 1863. p. 2.

${ }^{6}$ FREYRE, Sobrados e mucambos, p. 124-181.

${ }^{7}$ BUITONI, Imprensa feminina, p. 21-23.

${ }^{8}$ Jornal das Famílias, jan. 1863, p. 2.

9 FERRARO, "Analfabetismo e níveis de letramento no Brasil: o que dizem os censos", p. 35. O primeiro censo realizado no Brasil (1872) revelou que 82,3\% da população não sabia ler e escrever.
} 
revista publicava, em diferentes seções, ${ }^{10}$ textos do padre Francisco Bernardino de Souza que serviam como "um meio de ensinar a fé Cristã às leitoras, uma moral fundada principalmente na aceitação da vontade de Deus e dos pais e na inevitável punição aos pecadores". ${ }^{11}$ Os escritos do clérigo "consistiam em sentenças e trechos romanceados da Bíblia, numa linguagem mais acessível e com alto teor moralizador, destinadas a conscientizar as leitoras a respeito de suas obrigações". ${ }^{2}$ Os textos assinados pelo padre:

[...] além de instruir, procuravam demonstrar o quão terrível poderia ser a punição a quem não aprendesse. A lição moral mais empregada por ele era a de que somente o martírio poderia redimir o ser humano, de modo que, em muitas ocasiões, a morte aparecia como saída recorrente, principalmente quando se tratava de recuperar a honra de moças que se entregaram antes do casamento. $^{13}$

Os textos publicados por Machado de Assis no Jornal das Famílias parecem servir ao mesmo propósito de instruir e entreter. Essas histórias possuem caráter educativo. Nelas exaltam-se os bons costumes, condenam-se e punem-se os desvios, bem de acordo com os textos do padre Francisco Bernardino. Dos colaboradores esperava-se que povoassem de sonhos a imaginação das moças com uma "literatura amena de pura fantasia"14 -, sem desrespeitar a moral das famílias burguesas. Isso poderia gerar entre os assinantes ameaça de automática rescisão. ${ }^{15}$

Um trecho retirado do editorial de fevereiro de 1869 reforça essa ideia:

Graciosos romances têm sido publicados em nossas colunas nos seis anos de existência que já contamos, e parece-nos que nem uma só vez a delicada suscetibilidade de VV. EEx. tem sido ofendida.

Anedotas espirituosas e morais têm por certo causado a VV. EEx. o prazer que as pessoas de finíssima educação experimentam nesse gênero de amena literatura. ${ }^{16}$

Esses contos apresentam ensinamentos morais revelados no "triunfo constante do bem sobre o mal, e do amor, contanto que não fosse por interesse. A

\footnotetext{
10 Foram encontrados textos do padre Francisco Bernardino de Souza nas seções: "Romances e Novelas", "História", "Viagens" e "Mosaico".

${ }^{11}$ MAURO, O Brasil no tempo de Dom Pedro II (1831-1889), p. 228.

${ }^{12}$ CRESTANI, Machado de Assis no Jornal das Famílias, p. 64-65.

13 Ibidem.

14 PEREIRA, Machado de Assis: estudo crítico e biográfico, p. 134.

15 MASSA, A juventude de Machado de Assis. 1839-1870: ensaio de biografia intelectual, p. 459.

${ }^{16}$ Jornal das Famílias, jan. 1869, p. 37
} 
mulher inconstante e o caçador de dotes eram punidos, e os apaixonados fiéis e sinceros sempre viam a realização do seu amor, sob a forma de casamento". ${ }^{17}$ No conto "Luís Soares", o protagonista, boêmio e interesseiro, no passado havia desprezado o amor de sua prima Adelaide por ela não ser tão rica quanto ele. Já falido, descobre que o pai da moça lhe deixou uma grande herança e passa a demonstrar interesse em casar-se com ela. A prima não acredita no sentimento de Luís Soares. Ele é desmascarado, desprezado e suicida-se.

Para Jean-Michel Massa e Alfredo Bosi, no Jornal das Famílias Machado de Assis "aderiu às delícias do romanesco literário"18 e "à convenção estilística das leitoras de folhetins", ${ }^{19}$ por isso o amor idealizado, a instrução moral, a fuga da realidade, a reabilitação das personagens, geralmente por meio da morte características da literatura romântica ${ }^{20}$ - estão ainda fortemente presentes nos primeiros contos do autor. Para Jean-Michel Massa, "os contos de Machado de Assis publicados no Jornal das Famílias constituem um vade-mecum da arte de viver e de amar que se aconselha às brasileiras". ${ }^{21}$

Lúcia Miguel Pereira afirma que esses contos são

[...] anedotas passadas no mundo convencional onde os desgostos amorosos são os únicos sofrimentos, onde tudo gira em torno de olhos bonitos, de suspiros, de confidências trocadas entre damas elegantes. [...] os poucos tipos femininos foram copiados da galeria dos manequins românticos. Os homens são ainda mais estereotipados. ${ }^{22}$

As personagens femininas, nesses contos, não costumavam infringir o código de "boa conduta" estabelecido para elas. Não há, por exemplo, uma personagem como d. Eusébia de Memórias póstumas de Brás Cubas, cuja filha, Eugênia, era ilegítima, fruto de um caso com Villaça, um homem casado. As mulheres, nesses primeiros escritos, parecem definidas por seu estado civil: são casadas, donzelas por casar ou viúvas. Suas fraquezas não costumam nascer da quebra do decoro, por vezes aparecem relacionadas ao excesso de vaidade, como em "O segredo de Augusta". Nesse conto a personagem título finge não ver o comportamento desregrado e adúltero do marido Vasconcelos, em troca de quantias vultosas gastas com vestidos.

Num raro exemplo de adultério feminino - embora não concretizado, efetivamente -, em "Confissões de uma viúva moça", a personagem Eugênia, após a

\footnotetext{
${ }^{17}$ MAURO, cit., p. 227.

18 MASSA, cit., p. 469.

${ }^{19}$ BOSI, Machado de Assis: o enigma do olhar, p. 75.

20 PINHEIRO, cit.

${ }^{21}$ MASSA, cit., p. 461.

${ }^{22}$ PEREIRA, Machado de Assis: estudo crítico e biográfico, p. 135.
} 
morte do marido, arrependida, decide contar à amiga Carlota como foi seduzida por Emílio, um amigo do falecido. Segundo a própria personagem, a narrativa é uma forma de alerta para que outras moças não tenham o mesmo destino:

Ganhei conhecer um homem cujo retrato trago no espírito e que me parece singularmente parecido com outros muitos. Já não é pouco; e a lição há de servir-me, como a ti, como às nossas amigas inexperientes. Mostra-lhes estas cartas; são folhas de um roteiro que se eu tivera antes, talvez não houvesse perdido uma ilusão e dois anos de vida. ${ }^{23}$

Alguns personagens masculinos, solteiros ou casados, gastam grandes quantias para manter um estilo de vida boêmio. São exemplos dessa conduta Luís Soares, no conto homônimo, Vanconcelos e Gomes, no conto "O segredo de Augusta". Esse tipo de conduta é reprovado pelo narrador ou por outras personagens e, ao final, esse comportamento é, geralmente, punido. Como dito anteriormente, Luís Soares não consegue casar-se com a prima e suicida-se. Os amigos Vasconcelos (homem casado) e Gomes (um dos mais notáveis representantes da boemia carioca) são chamados de velhacos por tentarem "dar o golpe" um no outro: Gomes pediu a mão de Adelaide, filha de Vasconcelos, interessado no dote que manteria o seu estilo de vida, uma vez que estava falido; Vasconcelos estava fortemente inclinado a autorizar o casamento, pois pensava em ter acesso à fortuna de Gomes, já que havia dilapidado todo seu patrimônio nas festas de "certa sociedade equívoca", e com vestidos para a mulher que, dessa forma, fingia não ver seus excessos. ${ }^{24}$ Além da resistência da mãe, que queria prolongar sua juventude evitando o casamento da filha, o plano dos amigos foi frustrado pela recusa de Adelaide em casar-se com um homem que não amava.

A presença assídua de Machado de Assis nas páginas de um periódico que tem como proposta editorial a difusão de uma ideologia que defendia a integridade do lar e da família revela que ele não teve problemas em seguir as regras impostas. Jean-Michel Massa chega a afirmar que o autor compartilhava da moral respeitada pelo periódico. ${ }^{25}$ No entanto, se na aparência os contos publicados por Machado no Jornal das Famílias seguiam as imposições editoriais, um outro olhar sobre esses escritos revela como o autor problematizou, nas narrativas publicadas ali, alguns temas aparentemente frívolos explorados pela revista.

De certa forma, os contos do autor ajudavam a propagar os códigos morais e sociais que regiam as relações interpessoais naquele momento, ${ }^{26}$ mas muitas vezes isso se dava por meio da zombaria. Para Sílvia Maria Azevedo, a paródia e a ironia

\footnotetext{
${ }^{23}$ Jornal das Famílias, abr. 1865, p. 98.

${ }^{24}$ ASSIS, Obra completa em quatro volumes, v. 2, p. 71.

${ }^{25}$ MASSA, cit., p. 459.

${ }^{26}$ BASTOS, "Leituras das famílias brasileiras no século XIX: o Jornal das Famílias (1863-1878)", p. 169-214.
} 
foram as saídas encontradas por Machado para injetar vitalidade literária a histórias criadas a partir de clichês. ${ }^{27}$ Assim como Azevedo, Jaison Luís Crestani ${ }^{28}$ defende que Machado de Assis assumiu uma postura subversiva em relação aos padrões de produção estabelecidos pela revista, sobretudo no que diz respeito a questões relacionadas à moralidade, à tendência romântica, à extensão das histórias, ao modo de caracterização das personagens e às formas de relacionamento com o leitor. Para ambos, no Jornal das Famílias, Machado de Assis investiu na problematização dos valores românticos, desconstruindo as mistificações e excessos idealistas, além de questionar o pacto ingênuo da leitura de folhetim, dominante nas narrativas da época, que pressupunha total credibilidade do narrador e apoiava-se na solução sentimental e edificante do final feliz e do respeito pela ordem familiar.

\section{Alusões à moda e a discussão sobre a educação das mulheres no conto "A mulher de preto"}

O conto "A mulher de preto" narra a história de desilusão amorosa do jovem Estêvão Soares, médico recém-formado que conhece na saída do teatro o deputado Meneses, originário do Norte, e com quem inicia uma promissora amizade. Estêvão e o deputado frequentam restaurantes e o teatro. É nesse último local que o rapaz vê uma "mulher vestida de preto que se achava em um camarote da primeira ordem". ${ }^{29}$ Encontra-a outra vez em um baile, descobrindo seu nome, Madalena, e sua condição, "uma viúva de trinta e quatro anos, bela como o dia, graciosa e terna". ${ }^{30}$ Apaixonado por essa mulher, alimenta a ideia de pedi-la em casamento, até que ela confessa sua história:

A viúva não era viúva; era mulher de Meneses; viera do Norte meses antes do marido, que só veio como deputado; Meneses, que a amava doidamente, e que era amado com igual delírio, acusava-a de infidelidade; uma carta e um retrato eram os indícios; ela negou, mas explicou-se mal; o marido separou-se e mandou-a para o Rio de Janeiro. Madalena aceitou a situação com resignação e coragem: não murmurou nem pediu, cumpriu a ordem do marido. Todavia Madalena não era criminosa; o seu crime era uma aparência; estava condenada por fidelidade de honra. A carta e o retrato não lhe pertenciam; eram apenas um depósito imprudente e fatal. Madalena podia dizer tudo, mas era trair uma promessa; não quis; preferiu que a tempestade doméstica caísse

\footnotetext{
${ }^{27}$ AZEVEDO, A trajetória de Machado de Assis: do Jornal das Famílias aos contos e histórias em livro, p. 672.

${ }^{28}$ CRESTANI, cit.

${ }^{29}$ ASSIS, cit., p. 49.

${ }^{30}$ Idem, p. 50.
} 
unicamente sobre ela. Agora, porém, a necessidade do segredo expirara; Madalena recebeu do Norte uma carta em que a amiga, no leito da morte, pedia que inutilizasse a carta e o retrato, ou os restituísse ao homem que lhos dera. Esta carta era uma justificação. Madalena podia mandar a carta ao marido, ou pedir-lhe uma entrevista; mas receava tudo; sabia que seria inútil, porque Meneses era extremamente severo. ${ }^{31}$

Madalena solicita que o médico advogue sua causa junto a Meneses, para que possam reconciliar-se. Ele é bem-sucedido, o que conduz a história para o final que se mostra feliz para o casal, mas infeliz para o jovem, que, desapontado com seu primeiro amor, escolhe deixar o Rio de Janeiro e transferir-se para Minas Gerais.

Após mostrar as circunstâncias da amizade entre Estêvão e Meneses, o narrador faz uma breve caracterização do médico:

[...] tinha a tez pálida e a cabeça pendia-lhe um pouco para a frente pelo longo hábito da leitura. Mas esses vestígios de uma longa aplicação intelectual não lhe alteraram a regularidade e harmonia das feições, nem os olhos perderam nos livros o brilho e a expressão. Era, além disso, naturalmente elegante, não digo enfeitado, que é coisa diferente: era elegante nas maneiras, na atitude, no sorriso, no trajo, tudo mesclado de uma certa severidade que era o cunho do seu caráter. Podia-se notar-lhe muitas infrações ao código da moda; ninguém poderia dizer que ele faltasse nunca às boas regras do gentleman. ${ }^{32}$

Essa caracterização inicial, além de mostrar que Estêvão Soares era um intelectual - "desde os dezesseis anos sua vida foi um estudo constante, aturado e profundo";3 estudou medicina, matemática e literatura -, indica que o personagem tinha uma elegância natural, que não carecia de artifícios, tanto que cometia muitas infrações aos códigos da moda e ainda assim era "elegante no trajo". A descrição da aparência de Estevão alinha-se com sua opinião sobre a valorização excessiva da moda:

[...] uma menina [...] que em matéria de arte só conhece os figurinos parisienses; que deixa as calças para entrar no baile, e que antes de suspirar por um homem, examina-lhe a correção da gravata, e o apertado do botim; [...] esta menina pode vir a ser um esplêndido ornamento de salão e até uma fecunda mãe de família, mas nunca será uma mulher. ${ }^{34}$

\footnotetext{
${ }^{31}$ Idem, p. 59.

32 Idem, p. 45.

33 Ibidem.

${ }^{34}$ Idem, p. 46.
} 
Ao mesmo tempo que confirma uma postura de despreocupação com os códigos do vestuário, o trecho acima revela que o médico idealiza a mulher e espera encontrar uma que não note ou corrija suas infrações relacionadas à moda vigente. Além disso, a citação encerra uma crítica à educação que as mulheres recebiam - que privilegiava as frivolidades em detrimento de questões mais substanciais como as artes. Como vimos, o tipo de educação criticada era preocupação central do Jornal das Famílias, cuja proposta era instruir as mulheres para a manutenção da submissão e do desempenho de seu papel na família.

No entanto, o conteúdo do periódico não é produto de um projeto isolado de Garnier. O processo de reeuropeização ${ }^{35}$ por que passava a sociedade brasileira do período provocou, pouco a pouco, uma série de mudanças nos hábitos coloniais, que repercurtiram sobre a família. É nessa conjuntura que surge essa revista, investindo em artigos sobre medicina doméstica e as campanhas de moralização e higiene da coletividade. Embora na França essas discussões tenham se originado no século XVII, ${ }^{36}$ é só no século XIX que a educação das mulheres (burguesas) entra em pauta como parte do projeto civilizatório, em curso no Brasil naquele momento. Portanto, a posição de Estevão, claramente descrito como um intelectual, representa uma opinião discordante da proposta sobre a educação das mulheres: postula que elas deveriam receber instrução que permitisse ser mais que ornamento de salão.

Segundo o narrador, Estêvão tinha "ideias singulares"37 sobre a mulher e o amor que eram reflexo de suas leituras sentimentais:

Tais eram os sentimentos de Estêvão em relação ao amor e à mulher. A natureza dera-lhe em parte esses sentimentos; mas em parte adquiriu-os ele nos livros. Exigia a perfeição intelectual e moral de uma Heloísa; e partia da exceção para estabelecer uma regra. Era intolerante para os erros veniais. Não os reconhecia como tais. Não há erro venial, dizia ele, em matéria de costumes e de amor. ${ }^{38}$

O médico idealizava o amor com base na vaga ideia que tinha do relacionamento de seus pais:

\footnotetext{
${ }^{35}$ FREYRE, cit., p. 159. O autor chama de "reeuropeização" a série de mudanças implementadas pelo governo que marcaram a transição da vida patriarcal rural para a sociedade urbana na primeira metade do século XIX. Essas mudanças valorizavam hábitos, costumes, modas e o consumo de produtos europeus. "Reeuropeização acentue-se sempre - no sentido inglês e francês; e não no português. Ao contrário: reeuropeização em sentido quase sempre antiportuguês, como se para os anglófilos e francófilos mais exagerados a tradição portuguesa não fosse senão aparentemente europeia."

${ }^{36}$ LAJOLO \& ZILBERMAN, A formação da leitura no Brasil, p. 237.

${ }^{37}$ ASSIS, cit., p. 46.

${ }^{38}$ Idem, p. 46.
} 
Até aos vinte anos foi ele testemunha do que era a santidade do amor mantido pela virtude doméstica. Sua mãe, que morrera com trinta e oito anos, amou o marido até os últimos dias, e poucos meses lhe sobreviveu. Estêvão soube que fora ardente e entusiático o amor de seus pais, na estação do noivado, durante a manhã conjugal; conheceu-o assim por tradição; mas na tarde conjugal a que ele assistiu viu o amor calmo, solícito e confiante, cheio de dedicação e respeito, praticado como um culto; sem recriminações nem pesares, e tão profundo como no primeiro dia. Os pais de Estêvão morreram amados e felizes na tranquila serenidade do dever. ${ }^{39}$

Cabe destacar aqui duas passagens da citação acima que revelam uma provocação do narrador e colocam em xeque as convicções de Estêvão sobre o amor dos pais: a certeza que o jovem tinha sobre os primeiros anos da relação dos pais foi conhecida por tradição; em outras palavras, ele "ouviu falar", não vivenciou. A passagem "os pais de Estêvão morreram amados e felizes na tranquila serenidade do dever" parece irônica por sugerir que o casamento dos pais tenha sido por conveniência, como era costume, e não necessariamente por amor, como pensava o rapaz.

Como vimos, muito do que Estêvão julgava saber das relações amorosas nasceu de suas leituras românticas e das ideias que tinha do amor dos pais. Ele era convicto de que com a sua "morrera a última família, e fora com ela a derradeira tradição do amor". ${ }^{40}$ Sendo assim, o "que era preciso para derrubar todo este sistema, ainda que momentâneo? Uma coisa pequeníssima: um sorriso e dois olhos". ${ }^{4}$ "Madalena era excessivamente bela, embora mostrasse no rosto sinais de longo sofrimento. Era alta, cheia, tinha um belíssimo colo, magníficos braços, olhos castanhos e grandes, boca feita para ninho de amores." 42

As roupas pretas da esposa de Meneses ajudaram a iludir Estêvão, já que tradicionalmente o preto é a cor do luto no Ocidente, e o médico, como visto, era ligado às tradições. Madalena vestia-se desse modo talvez para externar um sentimento genuíno de tristeza e respeito ao marido, que a julgava infiel e de quem desejava reaproximar-se, já que a vestimenta é uma linguagem simbólica, um estratagema de que as pessoas sempre se serviram para tornar inteligível uma série de ideias, incluindo-se o estado emocional. ${ }^{43}$ Mas ao longo do conto é possível notar muitos indícios de que, após conhecer o médico e saber de sua relação com Meneses, a "falsa viúva" empenhou-se em seduzi-lo: "Quando entrou em casa achou uma carta para ele; a letra, que lhe era desconhecida, estava traçada

\footnotetext{
${ }^{39}$ Idem, p. 46-47.

${ }^{40}$ Idem, p. 47.

${ }^{41}$ Ibidem.

42 Idem, p. 53.

${ }^{43}$ SOUZA, cit., p. 125.
} 
com elegância e cuidado: a carta recendia de sândalo". ${ }^{44}$ Uma carta perfumada para convidá-lo para um chá com outros convivas. No entanto, ao chegar a casa encontrou apenas a "viúva" e seu filho. Ela justificou que havia desconvidado os demais pois encontrava-se enferma:

- Naturalmente; eu não lhe mandei dizer nada. Era a primeira vez que o convidava; não queria por modo algum arredar de casa um homem tão distinto.

Estas palavras de Madalena não valiam coisa alguma, nem mesmo como desculpa, porque a desculpa era fraquíssima.

Estêvão compreendeu logo que havia algum motivo oculto. Seria o amor? Estêvão pensou que era [.... ${ }^{45}$

Estêvão mostra-se ingênuo, e Madalena explora essa característica do rapaz para reaproximar-se do marido. A cada visita, Madalena prolongava a angústia do médico. Ela sabia de sua amizade com Meneses e ainda assim insistia em convidálo para sua casa sem revelar suas reais intenções. Estêvão, inclusive, menciona a relação com Meneses e sugere apresentá-lo a Madalena, que convenientemente adia o encontro.

Quando Madalena finalmente confessa sua história, Estêvão não duvida de sua índole, mesmo tendo sido apresentado pelo narrador como intolerante, o que não confirma a inocência da "viúva", mas reforça a ideia de que ela escolheu a alma perfeita para interceder por ela. Estêvão era ingênuo e estava apaixonado.

Machado criou um personagem que critica elementos da educação das moças de seu tempo, como aqueles propagados pelo próprio periódico no qual o conto foi publicado, mas, ao mesmo tempo, tira dele a credibilidade ao caracterizálo como um sujeito crédulo e inexperiente.

A apresentação de um personagem como Estêvão Soares, um intelectual simplório, por assim dizer, que é enganado pelo tipo que julgava ser o ideal, e que expõe opiniões, de certa forma progressistas, sobre a educação do sexo feminino, problematiza, mesmo que em tom de zombaria, a própria ideia da competência dos homens para decidir o destino das mulheres.

A simplicidade e a severidade de Estêvão, demonstradas na pouca importância que este destina aos assuntos da moda, poderiam revelar uma alma mais atenta a questões humanas, capaz de abdicar de sua própria felicidade para unir a mulher amada ao melhor amigo. No entanto, Estêvão mostra-se ingênuo mesmo antes de ser atraído para a casa de Madalena, e isolar-se após unir o casal pode significar apenas que ele estava envergonhado: "Não era pois somente o amor de Estêvão que sofria; era também o seu amor-próprio. Estêvão facilmente

${ }^{44}$ Idem, p. 51.

${ }^{45}$ Idem, p. 53. 
compreendeu que não fora atraído àquela casa para outra coisa". ${ }^{46}$

\section{Considerações finais}

Como se vê, nesse conto há uma crítica ao conteúdo frívolo do Jornal das Famílias, que acaba relativizada pelo tom de zombaria revelado na caracterização da própria personagem que faz a crítica.

Além disso, há uma espécie de inversão dos papéis: quando o mais comum nas narrativas românticas era a mulher pálida e ingênua, o conto ora analisado apresenta um personagem masculino pálido, que formava suas convicções sobre o amor a partir de leituras românticas. Há também uma crítica à excessiva idealização do par amoroso. Estevão tinha muitas convicções acerca do amor e das mulheres, mas acabou enganado por uma que, ironicamente, era exatamente a que sempre idealizou.

Estêvão não se preocupa com a moda, nem parece interessado em questões financeiras, o que poderia levar as leitoras sonhadoras a vê-lo como um contraponto a outros personagens nos contos anteriormente citados, como Luís Soares ("Luís Soares") ou Gomes ("O segredo de Augusta"). Mas sua caracterização sugere a figura de um tolo.

Por fim, é possível dizer que, explorando os próprios temas disseminados pela revista, o autor escrevia ficção e, ao mesmo tempo, produzia ironia. ${ }^{47}$ Assim, adequou-se às necessidades do periódico, sem ser servil às exigências editoriais. ${ }^{48}$

\section{Referências}

ASSIS, Machado de. Contos fluminenses. Obra Completa em quatro volumes. Rio de Janeiro: Nova Aguilar, 2008, v. 2.

AZEVEDO, Sílvia Maria. A trajetória de Machado de Assis: do Jornal das Famílias aos contos e histórias em livro. Tese (Doutorado em Teoria Literária e Literatura Comparada). São Paulo, USP, 1990, v. II.

BASTOS, Maria Helena Camara. "Leituras das famílias brasileiras no século XIX: o Jornal das Famílias (1863-1878)". Revista Portuguesa de Educação, 2002, v. 15, n. 2. Disponível em:

${ }^{46}$ Idem, p. 59.

${ }^{47}$ SILVA, Machado de Assis: do folhetim ao livro, p. 67. Embora a autora esteja tratando nessa obra sobre a revista $A$ Estação, que abrange os escritos da chamada "segunda fase" do autor, essa referência é, em certa medida, pertinente também para tratar a relação dos contos iniciais com o conteúdo do Jornal das Famílias.

48 MEYER, Caminhos do imaginário no Brasil, p. 100. 
https://www.lume.ufrgs.br/bitstream/handle/10183/28236/000390843.pdf? sequence=1. BOSI, Machado de Assis: o enigma do olhar. São Paulo: WMF Martins Fontes, 2007. BUITONI, Dulcília Schroeder. Imprensa feminina. São Paulo: Ática, 1986.

CRESTANI, Jaison Luís. Machado de Assis no Jornal das Famílias. São Paulo: Nankin; Edusp, 2009.

FERRARO, Alceu Ravanello. "Analfabetismo e níveis de letramento no Brasil: o que dizem os censos". Educação e Sociedade, São Paulo, v. 23, n. 81, dez. 2002.

FREYRE, Gilberto. Sobrados e mucambos. Rio de Janeiro: Record, 2000.

JORNAL das Famílias. Acervo da Hemeroteca Digital da Biblioteca Nacional. Disponível em: http://hemerotecadigital.bn.br/acervo-digital/jornal-familias/339776.

LAJOLO, Marisa; ZILBERMAN, Regina. A formação da leitura no Brasil. São Paulo: Ática, 1996.

MASSA, Jean-Michel. A juventude de Machado de Assis. 1839-1870: ensaio de biografia intelectual. São Paulo: Editora Unesp, 2009.

MAURO, Frédéric. O Brasil no tempo de Dom Pedro II (1831-1889). São Paulo: Companhia das Letras, 1991.

MEYER, Marlyse. Caminhos do imaginário no Brasil. São Paulo: Edusp, 2001.

PEREIRA, Lúcia Miguel. Machado de Assis: estudo crítico e biográfico. Belo Horizonte: Itatiaia; São Paulo: Edusp, 1988.

PINHEIRO, Alexandra Santos. Revista Popular (1859-1862) e Jornal das Famílias (18631878): dois empreendimentos de Garnier. Dissertação (Mestrado em Letras) - Faculdade de Ciências e Letras, Unesp, Assis, 2002.

SILVA, Ana Cláudia Suriani da. Machado de Assis: do folhetim ao livro. São Paulo: nVersos, 2015.

SOUZA, Gilda de Mello e. O espírito das roupas: a moda no século XIX. São Paulo: Companhia das Letras, 1987.

JOSILENE LUCAS DA SILVA é mestranda na Faculdade de Filosofia, Letras e Ciências Humanas da Universidade de São Paulo, com o projeto $O$ vestuário como elemento de caracterização de personagens nos contos iniciais de Machado de Assis, sob orientação da Profa. Dra. Cilaine Alves Cunha. Graduada e Licenciada em Letras pela Faculdade de Filosofia, Letras e Ciências Humanas (USP) e pela Faculdade de Educação (USP). Professora titular de cargo efetivo de Ensino Fundamental II e Médio na rede pública estadual de São Paulo. E-mail: josilene.silva@usp.br. 